\title{
Flexible Cystoscope-Assisted Treatment for Rectobulbar Fistula in Laparoscopic Anorectoplasty: A Case Report of an Excellent Technique
}

\section{Toshio Harumatsu, MD}

Department of Pediatric Surgery, Research Field in Medicine and Health Sciences, Medical and Dental Sciences Area, Research and Education Assembly, Kagoshima University, Kagoshima, Japan.

Taichiro Nagai, MD

Department of Pediatric Surgery, Research Field in Medicine and Health Sciences, Medical and Dental Sciences Area, Research and Education Assembly, Kagoshima University, Kagoshima, Japan.

\section{Keisuke Yano, MD}

Department of Pediatric Surgery, Research Field in Medicine and Health Sciences, Medical and Dental Sciences Area, Research and Education Assembly, Kagoshima University, Kagoshima, Japan.

Shun Onishi, MD, PhD

Department of Pediatric Surgery, Research Field in Medicine and Health Sciences, Medical and Dental Sciences Area, Research and Education Assembly, Kagoshima University, Kagoshima, Japan.

\section{Koji Yamada, MD}

Department of Pediatric Surgery, Research Field in Medicine and Health Sciences, Medical and Dental Sciences Area, Research and Education Assembly, Kagoshima University, Kagoshima, Japan.

Clinical Training Center, Kagoshima University Hospital, Kagoshima, Japan.

\section{Waka Yamada, MD, PhD}

Department of Pediatric Surgery, Research Field in Medicine and Health Sciences, Medical and Dental Sciences Area, Research and Education Assembly, Kagoshima University, Kagoshima, Japan.

Clinical Training Center, Kagoshima University Hospital, Kagoshima, Japan.

\section{Mitsuru Muto, MD, PhD}

Department of Pediatric Surgery, Research Field in Medicine and Health Sciences, Medical and Dental Sciences Area, Research and Education Assembly, Kagoshima University, Kagoshima, Japan.

\section{Tatsuru Kaji, MD, PhD}

Department of Pediatric Surgery, Research Field in Medicine and Health Sciences, Medical and Dental Sciences Area, Research and Education Assembly, Kagoshima University, Kagoshima, Japan.

Clinical Training Center, Kagoshima University Hospital, Kagoshima, Japan.

\section{Satoshi leiri, MD, PhD, FACS}

Department of Pediatric Surgery, Research Field in Medicine and Health Sciences, Medical and Dental Sciences Area, Research and Education Assembly, Kagoshima University, Kagoshima, Japan.

E-mail: sieiri@m.kufm.kagoshima-u.ac.jp

Presented at the 26th International Meeting of Pediatric Colorectal Club in Belgrade, Serbia. 
(c) Mary Ann Liebert, Inc. DOI: 10.1089/vor.2019.0612

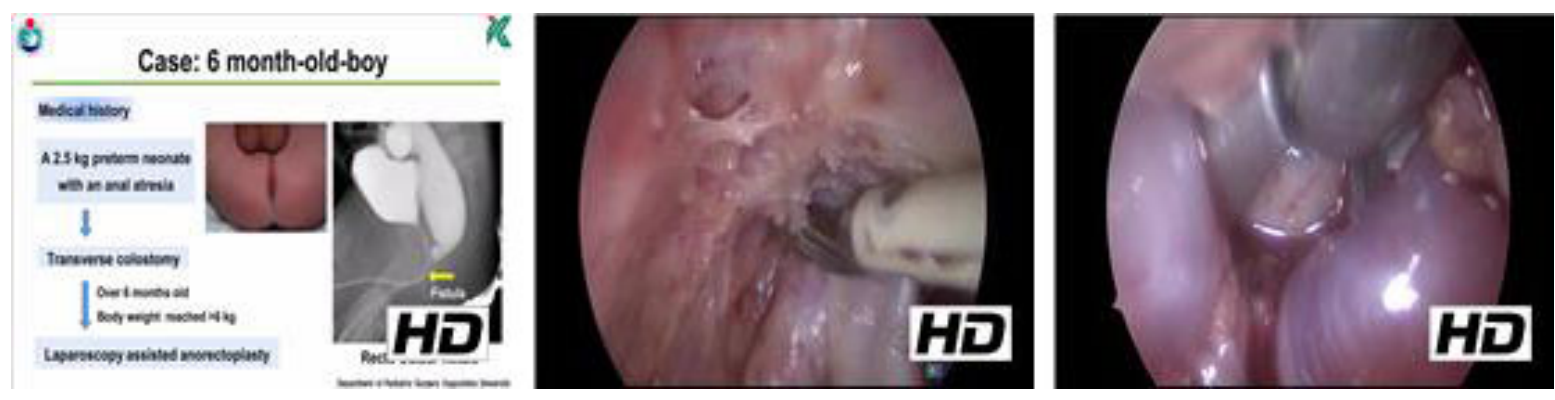

\section{Abstract}

Background: Nearly 20 years have passed since laparoscopically assisted anorectoplasty (LAARP) was first reported by Georgeson et al. ${ }^{1}$ and Georgeson. ${ }^{2}$ LAARP is now widely applied, especially for rectobladder neck fistula and rectoprostatic fistula. However, LAARP for rectobulbar fistula has not become standard practice because of the risk of urethra injury and incomplete fistula removal ${ }^{3-6}$ We herein report a useful technique for cystoscope-assisted rectobulbar fistula treatment in LAARP. ${ }^{7}$

Case Presentation: A 2.5-kg preterm male neonate was born with an anal atresia. In the neonatal period, left transverse colostomy was performed at the left upper quadrant. Before anorectoplasty, a distal colostogram was performed to confirm the type of anorectal malformation, and the patient was found to have rectobulbar fistula.

Operative Findings and Procedure: Under general anesthesia, the patient was placed in the lithotomy position. Before the laparoscopic procedure, the colostomy was temporarily closed, and the rectobulbar fistula orifice was confirmed using a 2.8-mm flexible cystoscope (KARLSTOZ, Tuttlingen, Germany). Pneumoperitoneum was established with $8 \mathrm{~mm} \mathrm{Hg}$ carbon dioxide inflation ( $3 \mathrm{~L} / \mathrm{min})$. A 5-mm port was inserted at the umbilicus by the open Hasson method for the operator's left hand. Three additional ports were then inserted under a 5-mm $30^{\circ}$ laparoscope: a 5-mm port at the right upper quadrant for the scope, a 5-mm port at the right lower quadrant for the operator's right hand, and a 3-mm port at the left umbilicus for the assistant. A $45^{\circ} 5-\mathrm{mm}$ scope was used to clearly view the deep pelvic space. The bladder was suspended to obtain a sufficient operative view. The perineal

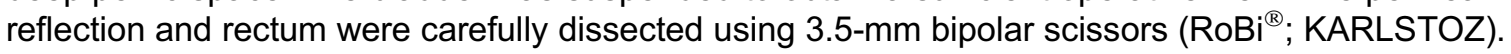
Keeping the dissection line between the prehypogastric nerve fascia and the fascia propria of the rectum is important for preserving the pelvic nerve. The rectobulbar fistula was ligated with 4-0 absorbable monofilament transfixing sutures (PDSII; Ethicon, Cincinnati, OH). The operator confirmed the stitch depth and complete adequate closure of the fistula from the urethral view under flexible cystoscope observation. A polymer clip (Weck Hem-o-lok Polymer Ligation System; Teleflex, Morrisville, NC) was additionally applied at the transfixing suture line. After transection of the fistula, the center of the muscle complex was confirmed from outside using an electrical nerve stimulator, and an 8-mm longitudinal incision was made. The muscle complex, including the puborectal sling, was then laparoscopically confirmed using a $3.5-\mathrm{mm}$ bipolar forceps $\left(\mathrm{RoBi}^{\circledR} ; \mathrm{KARLSTOZ}\right)$ connected to an electrical nerve stimulator. A pean was inserted to keep the center of the muscle complex away from the perineal wound under direct laparoscopic vision, and a 5-mm trocar was replaced through the center of the muscle complex. The rectum was pulled through, and the stump was sutured to the perineal skin.

Results and Conclusion: There were no intraoperative or postoperative complications. In the present case, the flexible cystoscope was effective and useful for the secure treatment of a fistula of laparoscopic anorectoplasty for an anorectal malformation patient with a rectobulbar fistula. Our technique decreased the risk of residual fistula.

Acknowledgment: We thank Mr. Brian Quinn for his comments and help with the article.

The authors declare no conflicts of interest in association with this study.

Runtime of video: 4 mins 59 secs

Presented at the 26th International Meeting of Pediatric Colorectal Club in Belgrade, Serbia. 
Keywords: laparoscope-assisted anorectoplasty, flexible cystoscope, anorectal malformation, rectobulbar fistula

\section{Cite this video}

Toshio Harumatsu, Taichiro Nagai, Keisuke Yano, Shun Onishi, Koji Yamada, Waka Yamada, Mitsuru Muto, Tatsuru Kaji, Satoshi leiri, Flexible Cystoscope-Assisted Treatment for Rectobulbar Fistula in Laparoscopic Anorectoplasty: A Case Report of an Excellent Technique, Videoscopy. 2019, DOI: 10.1089/vor.2019.0612.

\section{References}

1. Georgeson KE, Inge TH, Albanese CT. Laparoscopically assisted anorectal pull-through for high imperforate anus-A new technique. J Pediatr Surg 2000;35:927-930.

2. Georgeson K. Laparoscopic-assisted anorectal pull-through. Semin Pediatr Surg 2007;16:266-269.

3. Yamataka A, Lane GJ, Koga H. Laparoscopy-assisted surgery for male imperforate anus with rectourethral fistula. Pediatr Surg Int 2013;29:1007-1011.

4. Koga H, Okawada M, Miyano G, Doi T, Lane GJ, Yamataka A. Is measuring the residual rectourethral fistula during laparoscopically assisted anorectal pull-through for male high/intermediate type imperforate anus beneficial? Mid-term follow-up. J Pediatr Surg 2017;52:1994-1996.

5. Koga H, Chen SY, Murakami H, Miyano G, Ochi T, Lane GJ, Frykman PK, Yamataka A. Fact or myth? The long shared common wall between the fistula and the urethra in male anorectal malformation with urethral bulbar fistula. Pediatr Surg Int 2019;35:247-251.

6. Ishimaru T, Kawashima H, Tainaka $T$, et al. Laparoscopically assisted anorectoplasty for intermediate-type imperforate anus: Comparison of surgical outcomes with the sacroperineal approach. J Laparoendosc Adv Surg Tech A 2018 [Epub ahead of print]; DOI: 10.1089/ lap.2018.0330.

7. Kawano T, Idesako T, Eura R, et al. Cystoscopic-assisted laparoscopic resection of mullerian duct remnant in a male presenting with uterus and vagina. Videoscopy 2018;28(1): DOI: 10.1089/ vor.2017.0430.

Original Publication Date: 2019 